This item was submitted to Loughborough's Research Repository by the author.

Items in Figshare are protected by copyright, with all rights reserved, unless otherwise indicated.

\title{
Division, result and score margin alter the physical and technical performance of elite wheelchair tennis players
}

\section{PLEASE CITE THE PUBLISHED VERSION}

https://doi.org/10.1080/02640414.2020.1737361

\section{PUBLISHER}

Taylor \& Francis

\section{VERSION}

AM (Accepted Manuscript)

\section{PUBLISHER STATEMENT}

This is an Accepted Manuscript of an article published by Taylor \& Francis in Journal of Sports Sciences on 5 March 2020, available online: http://www.tandfonline.com/10.1080/02640414.2020.1737361.

\section{LICENCE}

CC BY-NC-ND 4.0

\section{REPOSITORY RECORD}

Mason, Barry, Rienk van der Slikke, Michael Hutchinson, and Vicky Goosey-Tolfrey. 2020. "Division, Result and Score Margin Alter the Physical and Technical Performance of Elite Wheelchair Tennis Players". Loughborough University. 
1 Division, result and score margin alter the physical and technical performance of elite

2 wheelchair tennis players

3 Original investigation

4 Barry S. Mason ${ }^{\mathrm{a}}$, Rienk M.A. van der Slikke ${ }^{\mathrm{b}}$, Michael J. Hutchinson ${ }^{\mathrm{a}}$, Vicky L. Goosey-

5 Tolfrey $^{\mathrm{a}}$

6 apeter Harrison Centre for Disability Sport, School of Sport, Exercise \& Health Sciences,

7 Loughborough University, Leicestershire, LE11 3TU, U.K.

$8{ }^{b}$ Faculty of Health, Nutrition \& Sports, Hague University of Applied Sciences, The Hague, The

9 Netherlands.

10 Corresponding author:

11 Dr Barry Mason

12 Peter Harrison Centre for Disability Sport, School of Sport, Exercise \& Health Sciences,

13 Loughborough University, Leicestershire, LE11 3TU, U.K

14 Email: b.mason@1boro.ac.uk

15 Phone $+44(0) 1509226387$

16

17 Running head: Physical and technical demands of elite wheelchair tennis

18 Abstract word count: 199

19 Manuscript word count: 4000

20 Figures: 4

21 Tables: 2 


\section{ABSTRACT}

24 This study determined the physical and technical demands of elite wheelchair tennis (WT) 25 match-play, how the demands differed between divisions (Men, Women, Quad) and the effect 26 that set result and score margin had on these demands. Seventeen WT players were monitored 27 during a singles competition. Physical measures of performance were analysed using an indoor 28 tracking system and inertial measurement units. Technical measures of performance were 29 examined using video analysis. Physical measures of performance differed by division (Men > 30 Women $>$ Quad) for most parameters. Rallies were longer during Men's $(P=0.027)$ and 31 Women's $(P=0.004)$ matches compared to Quad's and fewer shots were hit off 2 bounces in 32 Men's matches compared to Women's and Quad's $(P \leq 0.026)$. High-speed activity (HSA) 33 increased during losing sets $(P=0.043)$. Most physical measures of performance increased by 34 moderate to large effects during sets with a small score margin ( $\leq 3$ games differential). Mean 35 speed and HSA were similar during losing sets, regardless of margin, but decreased (large 36 effects) when winning by a large margin. This study demonstrated the physical and technical 37 demands that elite WT players need to be prepared for and how situational factors can influence 38 these demands.

39

40 Keywords: Activity profiles, video analysis, disability sport, wheelchair athletes, sports 41 performance 
43

44

45

46

47

48

49

50

51

52

53

54

55

56

57

58

59

60

61

62

63

64

65

66

67

\section{INTRODUCTION}

Wheelchair tennis (WT) is a court-based wheelchair sport that has been included at the Paralympic Games since 1992. It is played on the same size court, using the same scoring system and rules as the able-bodied version of the sport. The only exception is that two bounces of the ball are permitted during WT and a classification system is used to categorise athletes according to the severity of their physical impairment. Athletes with a permanent lower limb impairment (e.g. lower limb amputation; spinal cord injury - paraplegia) are eligible to compete in the 'Open' division, of which a separate category exists for both men and women. Athletes with a permanent lower and upper limb impairment (e.g. cerebral palsy; spinal cord injury tetraplegia) compete in a Quad division, where men and women compete together (International Tennis Federation, 2019).

4

WT has been described as an intermittent, multidirectional sport which is predominantly aerobic-based with short periods of high intensity activity interspersed (Croft, Dybrus, Lenton, \& Goosey-Tolfrey, 2010; Roy, Sayers Menear, Schmid, Hunter, \& Malone, 2006; Sindall et al., 2013b), and significant skill-based challenges also imposed on players during match-play (Filipcic \& Filipcic, 2009; Sanchez-Pay, Torres-Luque, \& Sanz-Rivas, 2016; Sanchez-Pay, Torres-Luque, \& Sanz-Rivas, 2017). Previous research into the physical demands of WT has revealed that players typically cover distances of $2816 \pm 844 \mathrm{~m}$ at a mean speed of $0.7 \pm 0.2 \mathrm{~m} \cdot \mathrm{s}^{-1}$ and reach peak speeds of $3.4 \pm 0.4 \mathrm{~m} \cdot \mathrm{s}^{-1}$ (Sindall et al., 2013b), with average heart rates equivalent to $66-75 \%$ of peak heart rate during singles match-play (Croft et al., 2010; Roy et al., 2006; Sanchez-Pay et al., 2016). Technical analysis has often been limited to temporal parameters, with rallies typically shown to last less than 6 secs and be completed in 3 strokes or less (Filipcic \& Filipcic, 2009; Sanchez-Pay et al., 2016; Sanchez-Pay et al., 2017). However, much of this research has focused solely on male WT players and if female 
68

or Quad players have been included, few comparisons have been made between the divisions. Only Sanchez-Pay et al. (2017) compared technical differences between Men's and Women's matches and revealed that rallies lasted longer during Women's matches. To individualise exercise prescription, a thorough examination of both the physical and technical demands across divisions is needed.

To further optimise the training environment, it is also important to establish which aspects of performance, both physical and technical, are most associated with successful performance in WT. Previous research has typically identified key performance indicators within sports by exploring what higher ranked or winning teams/players do differently to lower ranked or losing teams/players (Davis, Wittekind, \& Beneke, 2013; Hoppe, Baumgart, \& Freiwald, 2016; Rhodes, Mason, Malone, \& Goosey-Tolfrey, 2015). From a physical perspective, Sindall et al. (2013a) revealed that high ranked (top 25 in the world rankings) WT players covered more distance, at a higher mean speed and reached higher peak speeds than low ranked (outside top 350 in the world rankings) players. However, a direct relationship between increased physical activity profiles and successful performance cannot be made due to the large disparity and heterogeneity between ability levels of the high and low ranked groups used. In addition, Sindall et al. (2013a) observed that match result had no significant bearing on activity profiles. Alternatively, in able-bodied sports, the result and margin of the result have both been shown to influence the physical and technical demands imposed on athletes (Gabbett, 2013; Lupo, Condello, Capranica, \& Tessitore, 2012; Sullivan et al., 2014). Sullivan et al. (2014) demonstrated that although activity profiles and technical skill involvements were elevated during losing quarters of Australian football, smaller score margins also resulted in increased activity profiles yet with decreased efficiency of technical skills. Whereas larger score margins have been associated with increased physical demands 
93 during rugby league (Gabbett, 2013). Different trends across different sports highlight the need

94 for sport-specific research into the impact of situational variables on performance.

95

Subsequently, the aim of the current study was to firstly establish the physical and

97 technical demands of elite WT players and examine how these demands differ between

98 divisions. A secondary aim was to determine the impact of set result and score margin on these parameters. Discrepancies between divisions as well as the type of adaptation (physical or technical) could guide athletes and coaches in their match preparations.

101

102 METHODS

103 Participants

104 Seventeen international WT players (age $=30 \pm 8 \mathrm{yrs}$ ) participated in the study and included players from the Men's $(n=7)$, Women's $(n=6)$ and Quad $(n=4)$ divisions. 5/7 Men and 4/6 Women were strength impaired as a result of paraplegia from a spinal cord injury, with 2/7 Men and 2/6 Women lower-limb deficient. All Quad players were male and 3/4 had tetraplegia from spinal cord injuries. The mean age of each division was $29 \pm 9$ yrs, $28 \pm 6$ yrs and $35 \pm 6$ yrs for Men, Women and Quad's respectively. The study was approved by the local ethical advisory committee. All players provided written informed consent prior to the competition.

\section{Procedures}

113 Physical and technical performance data were collected during the NEC Wheelchair Tennis 114 Masters 2017. This singles competition includes the top 8 ranked players in the world for the

115 Men's and Women's divisions and top 6 for the Quad division and is played on indoor hard 116 courts. Physical measures of performance (distance, speed, acceleration and rotational metrics)

117 were collected using a radio frequency based indoor tracking system and inertial measurement 
118 units. Technical measures of performance (winners, errors, strokes per rally etc.) were collected 119 via video analysis. A total of 22 matches were collected, resulting in 73 individual sets of data.

120 All data were analysed with regards to i) the result of each set (win/loss) and ii) the margin of 121 the set result (small $\leq 3$ games differential; large $>3$ games differential).

\section{Measures and data processing}

Activity profiles were measured using a radio-frequency, indoor tracking system (ITS) (Ubisense, Cambridge, U.K) sampling at $~ 16$ Hz. A single small (40x40x10mm), lightweight 127 (25g) tag was attached on/near the bar behind the backrest of each player. These tags communicate wirelessly with 6 sensors positioned around the perimeter of the court, as described previously (Rhodes, Mason, Perrat, Smith, \& Goosey-Tolfrey, 2014). Data collection commenced at the beginning and terminated at the end of each set and was paused during stoppages (e.g. between games and injury timeouts). During each set the total distance covered, mean speed, peak speed, time spent performing low $\left(\mathrm{LSA}<1.0 \mathrm{~m} \cdot \mathrm{s}^{-1}\right)$, moderate (MSA $1.0-$ $\left.1332.0 \mathrm{~m} \cdot \mathrm{s}^{-1}\right)$ and high $\left(\mathrm{HSA}>2.0 \mathrm{~m} \cdot \mathrm{s}^{-1}\right)$ speed activity and the relative number of HSA $\left(\mathrm{n} \cdot \mathrm{min}^{-1}\right)$ 134 performed was analysed. Players' wheelchairs were also equipped with three inertial measurement units (IMU) (Shimmer3, Shimmer Sensing, Ireland) sampling at $199.8 \mathrm{~Hz}$. One IMU was attached to the camber bar of the wheelchair with the remaining two fixed around the

137 axis of each wheel. All IMU data were filtered using a $2^{\text {nd }}$ order low-pass Butterworth filter 138 (25 Hz cut-off frequency), as described previously (van der Slikke, Berger, Bregman, \& Veeger, 139 2016), to quantify the mean acceleration, rotational velocity and rotational acceleration.

140 Turning direction was also quantified by the IMU, with a turn defined as a $160^{\circ}$ change in 141 either the direction of the racket (R) or non-racket (NR) hand. To obtain a measure of internal 142 load, players were asked to report an overall rating of perceived exertion (RPE) for each set 
143 using the CR-10 scale within 30 minutes after the match (Borg, 1998). This was then multiplied

144 by the set duration (minutes) to give a session RPE (sRPE) value (Foster et al., 2001).

145

All matches were filmed for live television and the footage was used for analysis of the

147 technical activities performed. Video footage was analysed using Dartfish TeamPro Data 6.0

148 (Fribourg, Switzerland) by two analysts familiar with the software and tennis. Descriptive 149 technical activities including the number of points per set, shots per set, strokes per rally, how many bounces shots were hit off and the type of stroke performed (forehand, backhand, volley

151 etc.) were coded. Activities relating to how points were won were also coded and included the

152 percentage of points won by the server and within the first two shots of the rally (serve or 153 return), as well as the type of winner and errors made. Both analysts re-coded 4 sets worth of 154 data from a random selection of matches so that the intra- and inter-observer reliability could be established. Intraclass correlation coefficients (ICCs) $\geq 0.94$ (intra-observer) $\geq 0.64$ (interobserver) were observed across all variables which was deemed acceptable based on similar

157 previous analyses (Mason, Altmann, \& Goosey-Tolfrey, 2018; Mason, van der Slikke, 158 Hutchinson, Berger, \& Goosey-Tolfrey, 2018). The type of groundstroke performed (topspin, 159 flat or slice) was also coded, however the inter-observer ICCs for these ranged between 0.34 1600.41 for forehands and $0.13-0.28$ for backhands. The agreement between observers was 161 deemed too low and subsequently the type of groundstroke was excluded from further analysis.

\section{Statistical analyses}

164 Data were presented as means \pm standard deviation (SD). All statistical analyses were conducted using the Statistical Package for the Social Sciences (version 23.0: SPSS, Chicago, IL). Shapiro-Wilk tests confirmed that data were normally distributed. Levene's tests 167 confirmed that variances in data were homogenous. A multivariate analysis of variance 
168 (MANOVA) was performed for all physical and technical measures of performance. Main 169 effects were calculated for division (Men, Women, Quad), result (win / lose) and score margin

170 (small / large) as were the interactions between each. Statistical significance was accepted as $171 P<0.05$. Post-hoc tests with Bonferroni's correction were applied to determine where

172 significant differences existed between divisions. Effect size (Cohen's d) was also calculated 173 to determine the magnitude of any differences in performance (Cohen, 1988) and were 174 categorised as trivial $(<0.2)$, small $(0.2-0.6)$, moderate $(0.6-1.2)$, large $(1.2-2.0)$ and very 175 large ( $>2.0)$ according to previous guidelines (Batterham \& Hopkins, 2006). The range within 176 which the true effect size existed was determined using $95 \%$ confidence intervals $(95 \% \mathrm{CI})$.

\section{$178 \quad$ RESULTS}

179 Activity profiles were higher during Men's matches in relation to both Women's and Quad's matches and during Women's matches in relation to Quad's matches for most parameters

181 (Table 1). sRPE was the only physical parameter not to differ significantly between divisions. 182 Fewer statistically significant differences between divisions were revealed for technical 183 measures of performance, with the majority occurring between Men and Women as well as 184 Men and Quad divisions (Table 2). Men hit fewer shots off 2 bounces, hit a lower percentage of forehands, won a higher percentage of points on serve and hit more volley winners than Women $(P \leq 0.035)$ and Quad's $(P \leq 0.022)$. Fewer strokes per rally were observed during

187 Quad matches compared to Men's $(P=0.027)$ and Women's $(P=0.004)$ matches. No further 188 statistically significant differences in technical performance were observed between Women 189 and Quad divisions (Table 2) 
A minimal number of physical and technical measures of performance were

194 significantly affected by set result (Figure 1). Players performed more HSA and made more errors during losing sets, with more winners and points won by the server during winning sets. However, the effect sizes of these differences were only small (Figure 1). The only significant 197 interactions between result and division were revealed for peak speed and the percentage of 198 points won by the server (Figure 2). Differences in peak speed during winning and losing sets 199 were trivial for Men ( $3.85 \pm 0.37$ vs. $3.83 \pm 0.26 \mathrm{~m} \cdot \mathrm{s}^{-1}$ respectively). Whereas small decreases 200 were revealed for Women $\left(3.32 \pm 0.27\right.$ vs. $3.44 \pm 0.24 \mathrm{~m} \cdot \mathrm{s}^{-1}$ respectively) and moderate 201 increases in peak speed were observed for Quad's ( $3.32 \pm 0.34 \mathrm{vs.} 3.02 \pm 0.16 \mathrm{~m} \cdot \mathrm{s}^{-1}$ respectively) 202 during losing sets compared to winning sets. Women and Quad's won a higher percentage of 203 points on serve during winning sets. Alternatively, this percentage was higher for Men during 204 losing sets (Figure 2).

205

Score margin had a larger bearing on performance measures than set result based on the magnitude of effect sizes observed (Figure 3). Activity profiles increased by a moderate to large effect during sets with a small score margin. The only technical parameters affected by 211 score margin were the points won by the server and the strokes per rally, which both increased 212 during sets with a small score margin, with a small to moderate effect (Figure 3). No significant 213 interactions existed between score margin and division. However, several significant 214 interactions existed between score margin and set result for physical aspects of performance 215 (Figure 4). Mean speed, LSA and HSA were not significantly different between losing sets, 216 regardless of margin. Whereas mean speed and HSA were lower and LSA greater when 217 winning by a large margin. Rotational velocity and rotational acceleration were not 
218 significantly different during winning sets, regardless of margin, yet both decreased during 219 losing sets with a large margin (Figure 4).

\section{DISCUSSION}

224 The current study was the first to investigate the physical and technical demands of elite WT 225 players and to differentiate the findings across the three different divisions. It was also the first 226 to consider the impact that set result and score margin can have on these demands during singles 227 competition. Large differences in physical rather than technical performance existed between 228 different divisions. Technical measures of performance were affected by set result to a greater 229 extent than physical performance. The opposite was true regarding score margin, whereby 230 activity profiles were elevated during sets with a small score margin, whereas little effect on 231 technical performance was observed. These findings provide coaches and practitioners with 232 pertinent information about the physical and technical demands placed upon WT players, how 233 these demands differ according to situational factors and what is most critical to successful 234 performance. This information should assist coaches with the planning of both physical and technical preparation strategies.

As anticipated, the physical demands of WT differed considerably amongst the 238 divisions. Activity profiles were elevated during the Open divisions (Men and Women) in 239 relation to players from the Quad division. The fact that Quad players covered less distance at 240 lower speeds is likely attributed to the reduction in physiological capacity and muscular 241 strength experienced by these individuals (Janssen, Dallmeijer, Veeger, \& van der Woude, 242 2002). Activity profiles were also elevated during Men's matches compared to Women's 
243 matches. In particular, Men's matches were played at a higher mean speed with more HSA 244 performed throughout. Although anthropometric data, such as height, body mass and limb

245 length were not available, it is likely that these factors along with strength were all superior in 246 male WT players as has been reported previously between genders (Cavedon, Zancanaro, \&

247 Milanese, 2018) and would most likely account for the elevated activity profiles observed. One

248 interesting finding that was not anticipated was that the rotational velocity during turning was 249 actually greater during Women's matches compared to Men's. Since a similar level of impairment can be expected between these two divisions, based on the range of health 251 conditions and impairments reported, it is likely that a lower body mass possessed by female 252 players may account for their greater rotational velocity. Rotational measures of performance 253 have not been objectively measured during competition, despite its perceived importance to 254 WT players (Mason, Porcellato, van der Woude, \& Goosey-Tolfrey, 2010), which 255 demonstrates the value of including IMUs alongside the global measures of external load 256 provided by the ITS (Mason et al., 2018; van der Slikke, Berger, \& Goosey-Tolfrey, 2017).

Despite the differences in activity profiles, internal workload did not differ significantly across the divisions. It has already been determined that gender impacts on muscular strength (Cavedon et al., 2018), potentially leading to the greater peak speeds found. Furthermore, both gender (van der Woude, Bouten, Veeger, \& Gwinn, 2002) and level of physical function 262 (Leicht, Tolfrey, Lenton, Bishop, \& Goosey-Tolfrey, 2013) impact on peak measures of 263 aerobic capacity and could explain the differences in absolute activity profiles found between 264 divisions. However, RPE has been shown to be similar at equal levels of relative exercise 265 intensity, irrespective of level of physical function (Leicht, Bishop, \& Goosey-Tolfrey, 2012). 
267 divisions, and that differences in activity profiles are related to the absolute level of physical 268 capacity.

269

270

Although a large number of differences in physical performance were observed

271 between the divisions, fewer differences in technical performance were identified. Quad

272 matches were typified by significantly shorter rallies than both Open divisions, whereas no

273 differences were identified between the number of strokes per rally for Men's and Women's

274 matches. This contrasts the only previous study that compared the technical differences of

275 Men's and Women's WT, whereby rally duration and shots per rally were both found to be

276 higher during female matches (Sanchez-Pay et al., 2017). It could be that a difference in

277 expertise accounted for the differences observed between studies, since the participants 278 investigated by Sanchez-Pay et al. (2017) were described as international, yet no information

279 about world rankings was available. Alternatively, male and female players in the current study 280 were all within the top-8 in the world rankings and at this level no differences in strokes per 281 rally existed.

282

283

Although 2 bounces are permitted during WT, only 10\% of groundstrokes were hit off

2 bounces in the Men's division, which was significantly lower than both the Women's and

Quad divisions. The greater speed and acceleration possessed by male players may partly account for this, with players more capable of moving towards and hitting the ball before a second bounce. However, it is also likely that a greater ball speed is achieved in the Men's game. Given the superior strength previously referred to, it is likely that male players generate more speed in their groundstrokes, as has been observed during the able-bodied game (Reid, Morgan, \& Whiteside, 2016), meaning that the ball will travel through to their opponent 291 quicker, lessening the likelihood of a second bounce. Another interesting technical difference 
292 identified between divisions was that more points were won by the server during Men's

293 matches in relation to Women's and Quad matches, where the receiver won a larger portion of

294 the points. This would seem to suggest that serving seems to be a disadvantage during

295 Women's and Quad matches rather than an advantage like it is for the Men. Greater service

296 speeds have previously been observed for men in able-bodied tennis (Reid et al., 2016), and

297 could account for the current findings, as a faster serve effectively gives the receiver less time

298 to hit an effective return. Whereas the reduced service speed expected during Women's and

299 Quad matches, likely puts the receiver in an advantageous position since they can move their

300 chairs prior to the serve being hit and then return the ball back to the server who has to get

301 started from a virtually static position after serving. The assumption that serving may be a

302 weakness for Women and Quad players is somewhat strengthened by the finding that Women

303 hit more return winners than Men. These findings echo the trends observed during able-bodied

304 tennis, whereby males win a higher percentage of points on serve than females and females

305 return a higher percentage of serves (Reid et al., 2016).

306

307 The final notable difference between divisions for aspects of technical performance was 308 the percentage of volleys performed and the number of volley winners observed. Although 309 statistically insignificant, moderate effect sizes were revealed for Men to hit a higher 310 percentage of volleys than Women and hit a significantly higher number of volley winners than

311 Women and Quad's respectively. It appeared that a conscious effort was employed by male 312 players to approach the net to win a point, which has been deemed an effective strategy during 313 able-bodied tennis (Reid et al., 2016). This style of play might again have been made possible 314 due to the greater activity profiles they elicit. 
Despite all of the aforementioned differences in physical and technical performance

317 between different divisions of WT, each division seemed to respond in a similar manner to the

318 situational factors monitored, since few interactions existed between result and division and

319 none existed between score margin and division. Independent of division, very few

320 performance differences were observed during winning and losing sets. From a physical

321 perspective, only the percentage and number of HSA increased during losing sets of tennis,

322 which would suggest that losing players are not in control of the rally and hence more high-

323 speed efforts are required to stay in the rallies. Alternatively, a larger number of technical

324 parameters were found to differ between winning and losing sets. In general, these results all

325 indicated that more winners were hit during winning sets and more errors made during losing

326 sets, which is not surprising. However, these findings may also suggest that technical

327 performance outweighs that of physical performance in WT players given their stronger

328 association to the outcome of sets. This is in line with what has previously been observed within

329 able-bodied tennis, where technical-tactical abilities are also said to dominate (Hoppe et al.,

330 2016; Reid et al., 2016).

In contrast to the findings observed for set result, score margin seemed to have a greater impact on physical rather than technical measures of performance. Activity profiles were

334 significantly elevated during sets where a small score margin existed. This increased external 335 load was also supported by a higher internal load, with higher sRPE values reported by players 336 when score margins were small. These findings could be partly due to the longer rallies 337 observed during sets with a small score margin. No previous studies in tennis, either WT or 338 able-bodied, have explored the impact of score margin on the physical and technical demands 339 of match-play. The only previous study to explore this phenomenon did so in Australian 
340 football, but still identified similar trends to the current study whereby small score margins had 341 more of an effect on physical measures of performance than technical (Sullivan et al., 2014).

342 Independent of division, a number of significant interactions existed between set result

344 and score margin for physical parameters of performance. Trivial to small differences were 345 observed for the mean speed, time spent performing LSA and HSA and the number of HSA 346 performed between small and large score margins during losing sets. However, the mean speed 347 and HSA increased and the LSA decreased when winning by a small margin compared to a 348 large margin. These observations and subsequent interpretations are consistent with the 349 previous discussions regarding the main effects for result. For example, when winning with a 350 large margin it is likely that the winning player is in control of the point so therefore requires 351 fewer HSA to retrieve and return balls, thereby performing greater LSA. During winning sets, 352 the degree of mean rotational velocity and acceleration were similar however when losing by 353 a large margin, these were reduced by a small and moderate effect respectively. This would 354 seem to emphasise the need for rapid rotational chair movements in WT since it was associated 355 with both winning conditions. The fact it was also present during losing sets where the score 356 margin was small would indicate that players movements and subsequent positioning was 357 appropriate. The unfavourable result could have just been down to an unfavourable few points 358 or poor shot selection at critical moments. Whereas the fact that rotational performance is 359 reduced when losing by a large margin would suggest that players are not even getting into 360 good positions frequently enough to be competitive during rallies. Subsequently rotational 361 performance and the use of IMUs for quantifying this, would seem of value for tennis coaches and practitioners to develop their players. 
In future, studies would be advised to monitor the type of groundstroke being performed

to establish whether a certain type of stroke (topspin, flat or slice) is played more by a certain division or associated with greater success than other strokes. In particular the inverted or 367 pronated backhand (topspin) has become a more common stroke over recent years and warrants 368 investigation. However, the inter-observer reliability for the detection of such shots was too 369 low for inclusion during the current study. Further studies of this nature would also be encouraged to synchronise the physical data with the technical data to provide coaches with

371 more context about where on court certain activities are being performed. Larger sample sizes

372 would have also been desirable for making comparisons across divisions, however this would 373 have been difficult given the homogenous nature of the high-ranked WT players investigated.

\section{CONCLUSIONS}

376 The current study has revealed that differences in activity profiles exist between divisions in 377 WT, although internal workload and technical performance are similar, as are the divisions 378 responses to result and score margin. Independent of division, increased technical rather than 379 physical performance seems paramount to set result. Although increased activity profiles are 380 required during sets with small score margins. These findings have important implications for

381 WT coaches and practitioners since the information presented demonstrates the physical and 382 technical demands that players need to be prepared for according to division and the situational 383 factors experienced during competition.

\section{REFERENCES}

386 Batterham, A. M., \& Hopkins, W. G. (2006). Making meaningful inferences about magnitudes. 
388 Borg, G. A. (1998). Borg's perceived exertion and pain scales. Champaign, IL: Human $389 \quad$ Kinetics.

390 Cavedon, V., Zancanaro, C., \& Milanese, C. (2018). Anthropometry, body composition and 391 performance in sport-specific field test in female wheelchair basketball players. Frontiers 392 in Physiology, 9, 568.

393 Cohen, J. (1988). Statistical power analysis for the behavioral sciences, $2^{\text {nd }}$ ed. Hillsdale, NJ: $394 \quad$ Lawrence Earlbaum Associates.

395 Croft, L., Dybrus, S., Lenton, J., \& Goosey-Tolfrey, V. (2010). A comparison of the 396 physiological demands of wheelchair basketball and wheelchair tennis. International 397 Journal of Sports Physiology and Performance, 5, 301-315.

398 Davis, P., Wittekind, A., \& Beneke, R. (2013). Amateur boxing: Activity profile of winners 399 and losers. International Journal of Sports Physiology and Performance, 8, 84-91.

400 Foster, C., Florhaug, J. A., Frankin, J., Gottschall, L., Hrovatin, L. A., \& Parker, S. (2001). A 401 new approach to monitoring exercise intensity. Journal of Strength and Conditioning $402 \quad$ Research, 15, 109-115.

403 Filipcic, T., \& Filipcic, A. (2009). Time characteristics in wheelchair tennis played on hard $404 \quad$ surfaces. Kinesiologie, 41, 67-75.

405 Gabbett, T. J. (2013). Influence of the opposing team on the physical demands of elite rugby 406 league match play. Journal of Strength and Conditioning Research, 27(6), 1629-1635.

407 Hoppe, M. W., Baumgart, C., \& Freiwald, J. (2016). Do running activities of adolescent and 408 adult tennis players differ during play? International Journal of Sports Physiology and 409 Performance, 11, 793-801.

410 ITF Wheelchair Tennis Classification $\quad$ Manual

411 https://www.itftennis.com/media/302189/302189.pdf. Accessed February 25, 2019. 
412 Janssen, T. W., Dallmeijer, A. J., Veeger, D. J., \& van der Woude, L. H. (2002). Normative 413 values and determinants of physical capacity in individuals with spinal cord injury. Journal 414 of Rehabilitation Research and Development, 39(1), 29-39.

415 Leicht, C. A., Bishop, N. C., \& Goosey-Tolfrey, V. L. (2012). Submaximal exercise responses 416 in tetraplegic, paraplegic and non spinal cord injured elite wheelchair athletes. Scandinavian 417 Journal of Medicine and Science in Sports, 22(6), 729-736.

418 Leicht, C. A., Tolfrey, K., Lenton, J. P., Bishop, N. C., \& Goosey-Tolfrey V. L. (2013). The verification phase and reliability of physiological parameters in peak testing of elite wheelchair athletes. European Journal of Applied Physiology, 113(2), 337-345.

421 Lupo, C., Condello, G., Capranica, L., \& Tessitore, A. (2012). Women's water polo World 422 Championships: Technical and tectical aspects of winning and losing teams in close and 423 unbalanced games. Journal of Strength and Conditioning Research, 28(1), 210-222.

424 Mason, B. S., Altmann, V. C., \& Goosey-Tolfrey, V. L. (2018). Understanding the impact of 425 trunk and arm impairment on wheelchair rugby performance during competition. 426 International Journal of Sports Physiology and Performance, Epub ahead of print: 427 doi:10.1123/ijspp.2018-0204.

428 Mason, B. S., Porcellato, L., van der Woude, L. H., \& Goosey-Tolfrey, V. L. (2010). A 429 qualitative examination of wheelchair configuration for optimal mobility performance in wheelchair sports: a pilot study. Journal of Rehabilitation Medicine, 42(2), 141-149.

431 Mason, B. S., van der Slikke, R. M. A., Hutchinson, M. J., Berger, M. A. M., \& Goosey-Tolfrey, 432 V. L. (2018). The effect of small-sided game formats on physical and technical performance 433 in wheelchair basketball. International Journal of Sports Physiology and Performance, $434 \quad 13(7), 891-896$.

435 Reid, M., Morgan, S., \& Whiteside, D. (2016). Matchplay characteristics of Grand Slam tennis: 436 Implications for training and conditioning. Journal of Sports Sciences, 34(19), 1791-1798. 
437 Rhodes, J. M., Mason, B. S., Malone, L. A., \& Goosey-Tolfrey, V. L. (2015). Effect of team 438 rank and player classification on activity profiles of elite wheelchair rugby players. Journal of Sports Sciences, 33(19), 2070-2078.

440 Rhodes, J. M., Mason, B. S., Perrat, B., Smith, M., \& Goosey-Tolfrey V. L. (2014). The validity 441 and reliability of a novel indoor tracking system for use within wheelchair court sports. 442 Journal of Sports Sciences, 32(17), 1639-1647.

443 Roy, J. L. P., Sayers Menear, K., Schmid, M. M. A., Hunter, G. R., \& Malone L. A. 444 (2006).Physiological responses of skilled players during a comptitive wheelchair tennis 445 match. Journal of Strength and Conditioning Research, 20(3), 665-671.

446 Sanchez-Pay, A., Torres-Luque, G., \& Sanz-Rivas, D. (2016). Match activity and physiological 447 load in wheelchair tennis players: a pilot study. Spinal Cord, 54, 229-223.

448 Sanchez-Pay, A., Torres-Luque, G., \& Sanz-Rivas, D. (2017). Activity patterns in male and 449 female wheelchair tennis matches. Kinesiologie, 49(1), 41-46.

450 Sindall, P., Lenton, J. P., Tolfrey, K., Cooper, R. A., Oyster, M., \& Goosey-Tolfrey, V. L. 451 (2013a). Wheelchair tennis match-play demands: Effect of player rank and result. 452 International Journal of Sports Physiology and Performance, 8, 28-37.

453 Sindall, P., Lenton, J. P., Whytock, K., Tolfrey, K., Oyster, M. L., Cooper, R. A., \& Goosey454 Tolfrey, V. L. (2013b). Criterion validity and accuracy of global positioning satellite and 455 data logging devices for wheelchair tennis court movement. Journal of Spinal Cord 456 Medicine, 36(4), 383-393.

457 Sullivan, C., Bilsborough, J. C., Cianciosi, M., Hocking, J., Cordy, J., \& Coutts, A. J. (2014). 458 Match score affects activity profile and skill performance in professional Australian $459 \quad$ Football players. Journal of Science and Medicine in Sport, 17, 326-331. 
460 van der Slikke, R. M. A., Berger, M. A. M., Bregman, D. J. J., \& Veeger H. E. J. (2016). From 461 big data to rich data: the key features of athlete wheelchair mobility performance. Journal 462 of Biomechanics, 49, 3340-3346.

463 van der Slikke, R. M. A., Mason, B. S., Berger, M. A. M., \& Goosey-Tolfrey, V. L. (2017). 464 Speed profiles in wheelchair court sports: A comparison of two methods for measuring 465 wheelchair mobility performance. Journal of Biomechanics, 65, 221-225.

466 van der Woude, L. H., Bouten, C., Veeger, H. E., \& Gwinn, T. (2002). Aerobic work capacity 467 in elite wheelchair athletes: A cross-sectional analysis. American Journal of Physical $468 \quad$ Medicine and Rehabilitation, 81(4), 261-271.

469

470

471

472 
473 Figure Legends:

474

475 Figure 1 Effect sizes $( \pm 95 \%$ CI) demonstrating the magnitude of statistically significant 476 performance differences between winning and losing sets of WT. A negative effect size 477 demonstrates performance measure was greater during losing sets and vice versa.

478

479 Figure 2 Significant interactions between result and division. Bars denote mean $( \pm$ SD). Effect 480 sizes $( \pm \mathbf{9 5} \% \mathrm{CI})$ signify magnitude of observed differences. A negative effect size demonstrates 481 performance was greater during losing sets and vice versa.

482

483 Figure 3 Effect sizes $( \pm 95 \%$ CI $)$ demonstrating the magnitude of statistically significant 484 performance differences between sets of WT with a small and large score margin. All positive 485 effect sizes indicate performance increased during sets with small score margins.

487 Figure 4 Performance measures where significant interactions between set result and score 488 margin were identified. Bars denote mean $( \pm \mathrm{SD})$. Effect sizes $( \pm 95 \% \mathrm{CI})$ signify magnitude of 489 observed differences. A negative effect size demonstrates performance was greater during sets 490 with a large score margin and vice versa. 


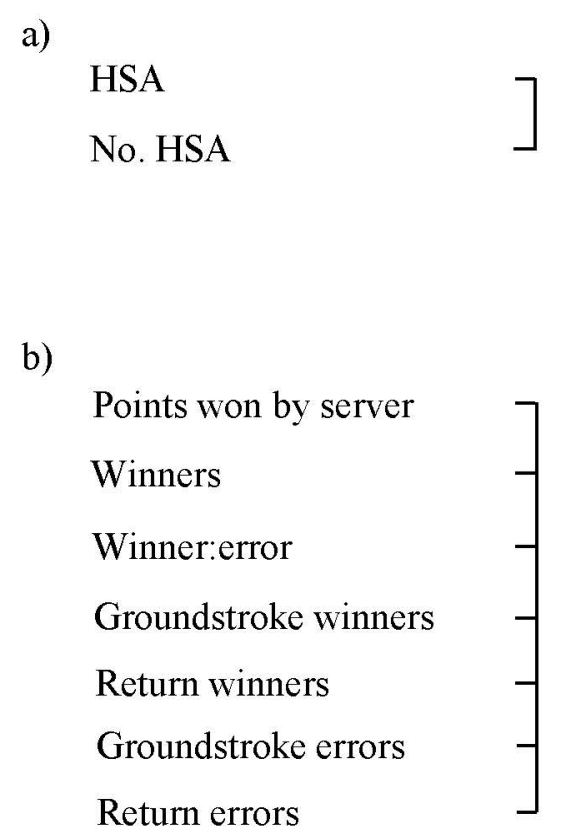

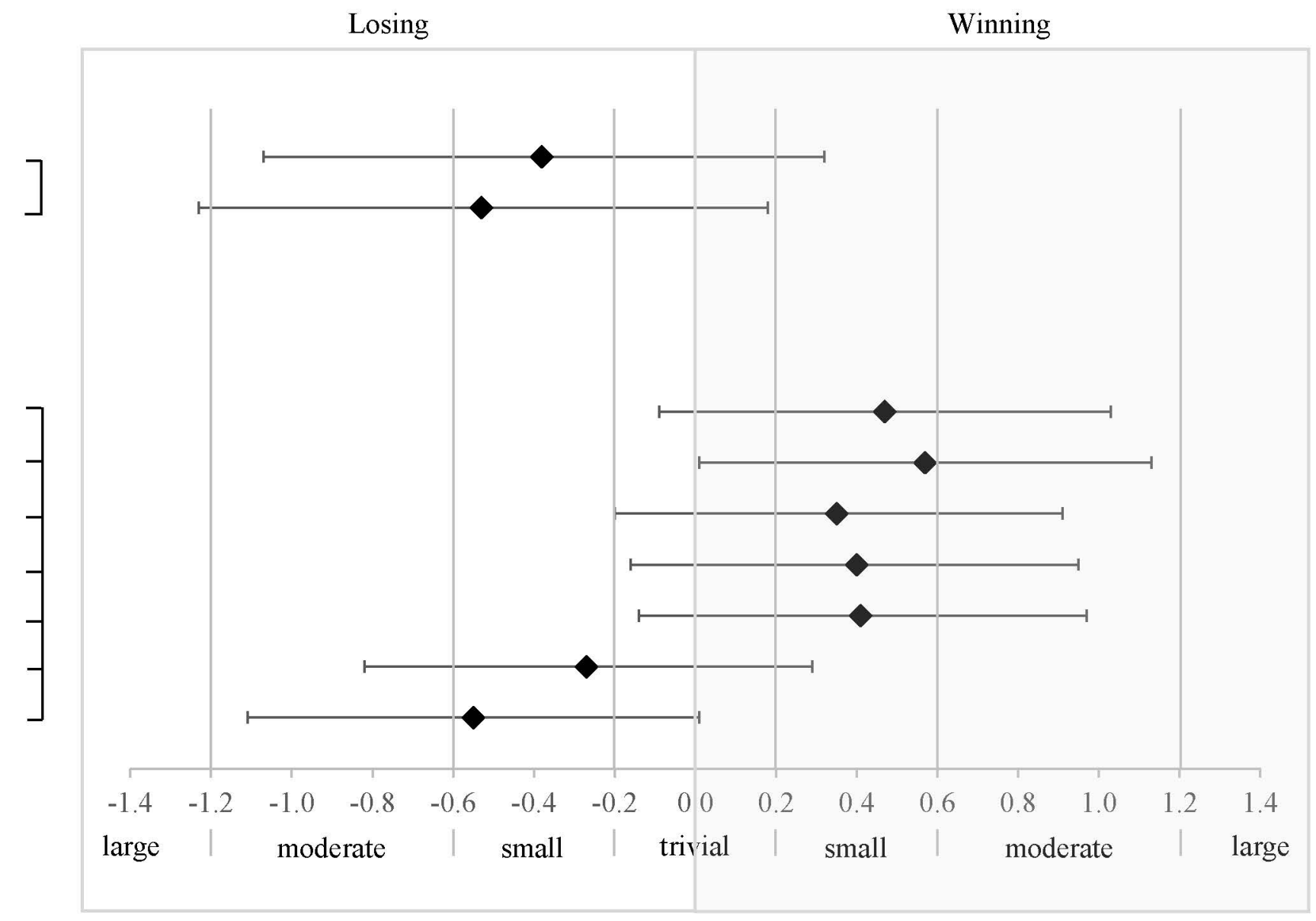


$\square \quad$ Winning $\square \quad$ Losing
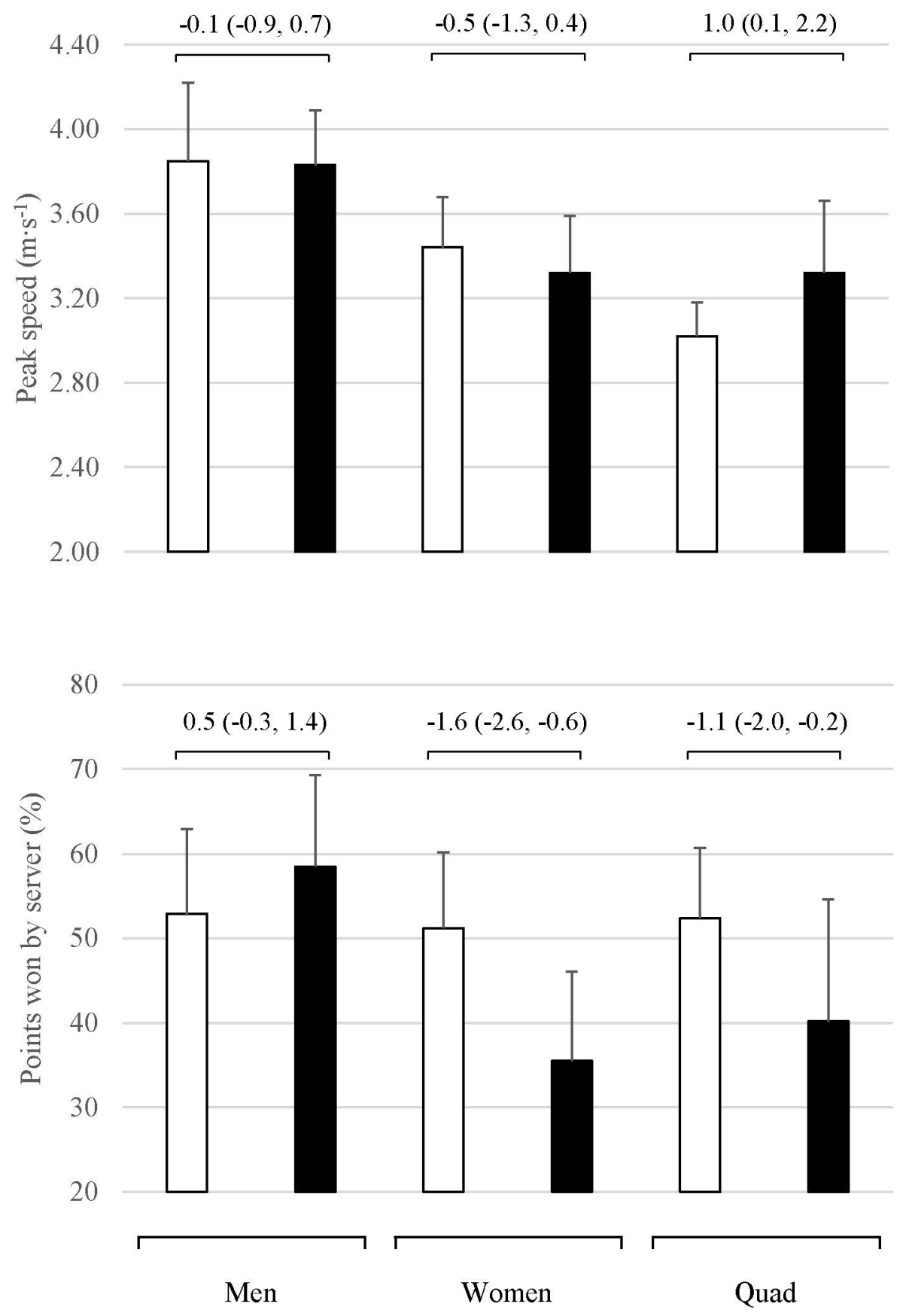
a)

Distance

Mean speed

Peak speed

HSA

No. HSA

Session RPE

b)

Points won by server

Strokes per rally

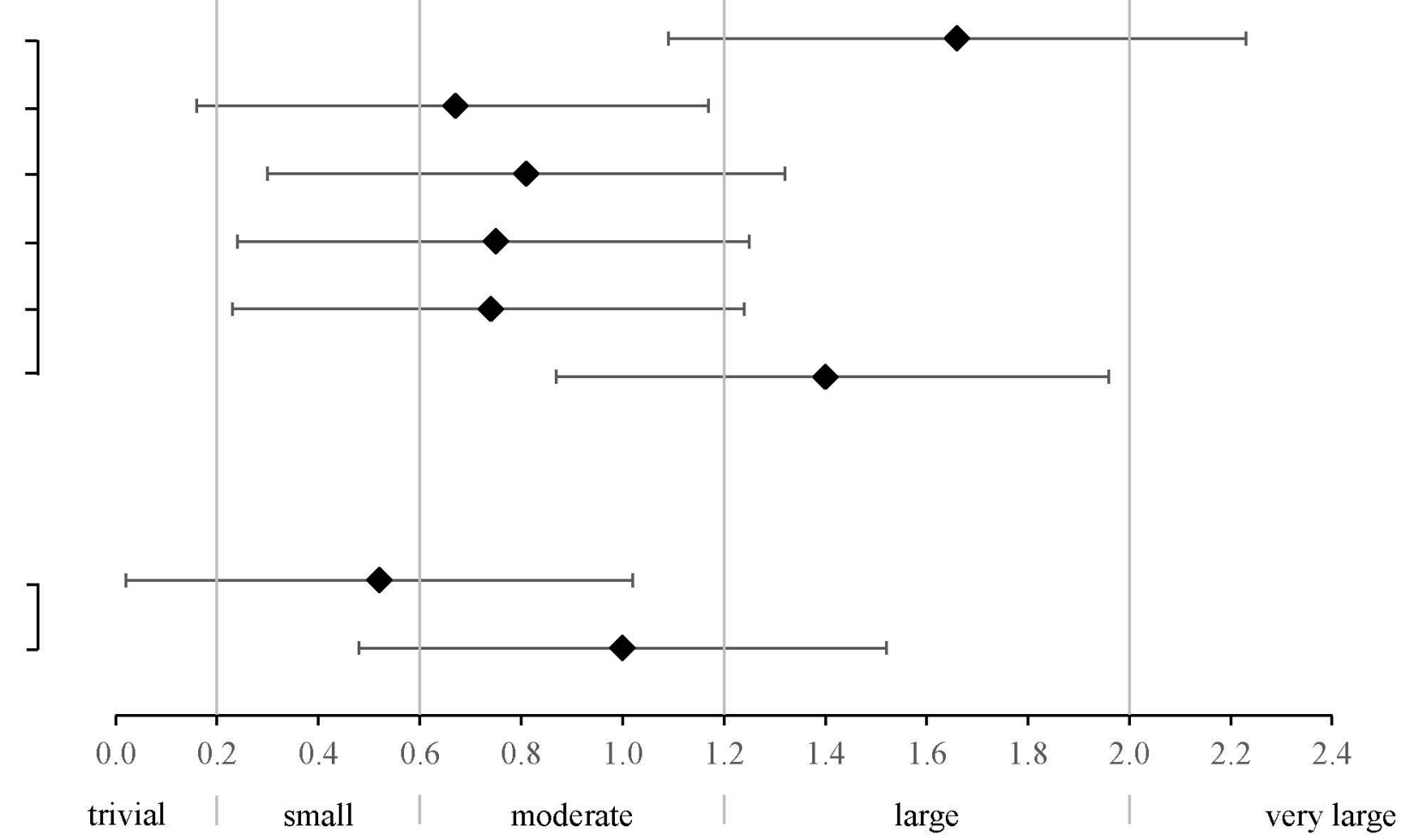



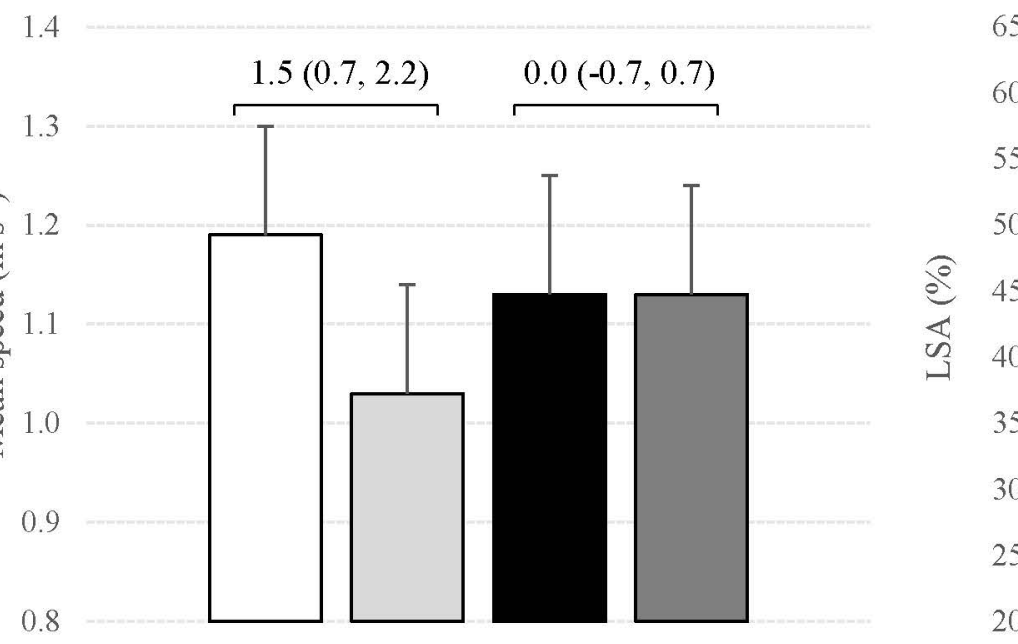

$$
\begin{array}{ll}
-1.0(-1.8,0.3) & 0.2(-0.5,0.9) \\
T &
\end{array}
$$
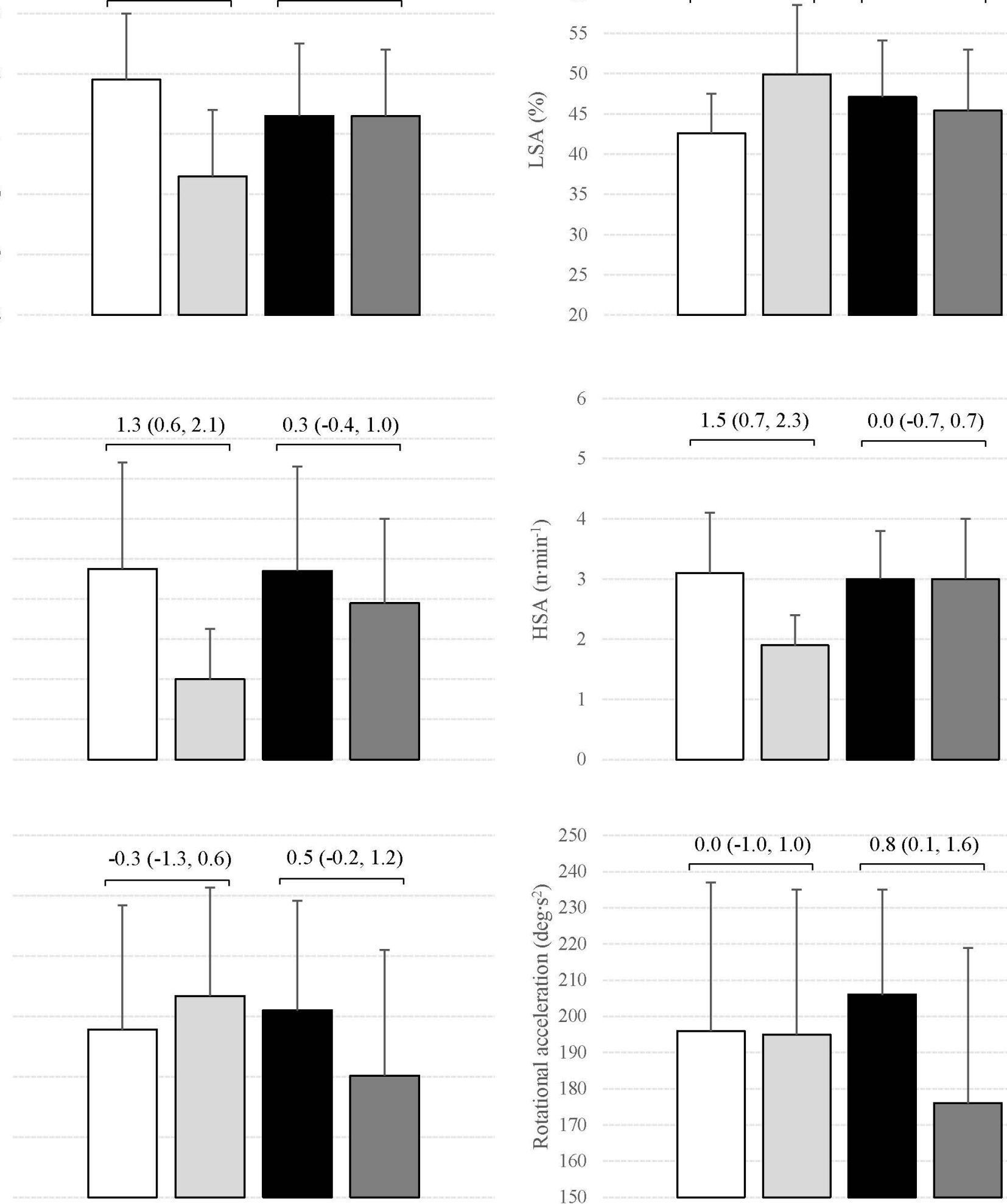
Table 1 Differences in physical aspects of performance during sets of WT from different divisions. Values presented are means $( \pm$ SD)

\begin{tabular}{|c|c|c|c|c|c|c|c|}
\hline & \multirow{2}{*}{$\begin{array}{c}\text { Main effect } \\
\text { (division) }\end{array}$} & \multirow[t]{2}{*}{ Men's } & \multirow[t]{2}{*}{ Women's } & \multirow[t]{2}{*}{ Quads } & \multicolumn{3}{|c|}{ Effect sizes $( \pm 95 \% \mathrm{CI})$} \\
\hline & & & & & Men vs. Women & Men vs. Quad & Women vs. Quad \\
\hline Duration (mm:ss) & 0.016 & $39: 18(12: 22)$ & $34: 01(10: 43)$ & $28: 50(08: 07)$ & $0.3(-0.3,0.8)$ & $1.1(0.4,1.8)^{*}$ & $0.9(0.2,1.6)^{*}$ \\
\hline Distance (m) & 0.005 & $2220(802)$ & $1841(648)$ & $1275(347)$ & $0.5(0.0,1.1)$ & $1.4(0.7,2.1)^{*}$ & $1.0(0.3,1.7)^{*}$ \\
\hline Mean speed $\left(\mathrm{m} \cdot \mathrm{s}^{-1}\right)$ & $<0.0005$ & $1.20(0.12)$ & $1.10(0.09)$ & $1.01(0.08)$ & $0.9(0.4,1.5)^{*}$ & $1.8(1.0,2.5)^{*}$ & $1.0(0.3,1.7)^{*}$ \\
\hline Peak speed $\left(\mathrm{m} \cdot \mathrm{s}^{-1}\right)$ & $<0.0005$ & $3.84(0.31)$ & $3.39(0.25)$ & $3.17(0.30)$ & $1.6(1.0,2.2)^{*}$ & $2.2(1.4,3.0)^{*}$ & $0.8(0.1,1.5)^{*}$ \\
\hline LSA $(\%)$ & 0.002 & $44.3(6.5)$ & $44.4(7.0)$ & $53.3(5.8)$ & $0.0(-0.5,0.6)$ & $1.4(0.7,2.2)^{*}$ & $1.4(0.6,2.1)^{*}$ \\
\hline $\operatorname{MSA}(\%)$ & 0.005 & $41.7(4.9)$ & $48.0(7.4)$ & $42.0(5.2)$ & $1.0(0.4,1.6)^{*}$ & $0.1(-0.6,0.7)$ & $0.9(0.2,1.6)^{*}$ \\
\hline $\operatorname{HSA}(\%)$ & $<0.0005$ & $14.1(4.3)$ & $7.6(1.7)$ & $4.8(1.3)$ & $2.0(1.3,2.6)^{*}$ & $2.6(1.7,3.5)^{*}$ & $1.8(1.0,2.6)^{*}$ \\
\hline No. HSA $\left(n \cdot \min ^{-1}\right)$ & $<0.0005$ & $3.5(0.7)$ & $2.5(0.7)$ & $1.7(0.4)$ & $1.4(0.8,2.0)^{*}$ & $2.9(2.0,3.8)^{*}$ & $1.3(0.6,2.0)^{*}$ \\
\hline Mean acceleration $\left(\mathrm{m} \cdot \mathrm{s}^{2}\right)$ & $<0.0005$ & $1.08(0.18)$ & $0.91(0.15)$ & $0.72(0.08)$ & $1.0(0.4,1.6)^{*}$ & $2.3(1.5,3.2)^{*}$ & $1.5(0.7,2.2)^{*}$ \\
\hline Turns $-\mathrm{R}\left(\mathrm{n} \cdot \mathrm{min}^{-1}\right)$ & $<0.0005$ & $5.6(0.5)$ & $6.2(1.1)$ & $4.9(0.8)$ & $0.7(0.2,1.3)$ & $1.1(0.4,1.8)^{*}$ & $1.3(0.6,2.0)^{*}$ \\
\hline Turns $-\mathrm{NR}\left(\mathrm{n} \cdot \mathrm{min}^{-1}\right)$ & 0.016 & $7.5(0.7)$ & $7.2(1.0)$ & $6.8(0.6)$ & $0.4(-0.2,0.9)$ & $1.0(0.4,1.7)^{*}$ & $0.5(-0.2,1.1)$ \\
\hline Rotational velocity $\left(\mathrm{deg} \cdot \mathrm{s}^{-1}\right)$ & $<0.0005$ & $72.1(5.0)$ & $82.4(8.9)$ & $63.7(4.9)$ & $1.5(0.8,2.1)^{*}$ & $1.7(0.9,2.4)^{*}$ & $2.4(1.6,3.3)^{*}$ \\
\hline Rotational acceleration $\left(\mathrm{deg} \cdot \mathrm{s}^{2}\right)$ & $<0.0005$ & $205(28)$ & $211(29)$ & $144(31)$ & $0.2(-0.4,0.7)$ & $2.1(1.3,2.9)^{*}$ & $2.3(1.4,3.1)^{*}$ \\
\hline Session RPE (au) & 0.175 & $136(68)$ & $101(76)$ & $94(32)$ & $0.5(-0.1,1.01)$ & $0.7(0.1,1.4)$ & $0.1(-0.6,0.8)$ \\
\hline
\end{tabular}

Turns - R: turns in the direction of the racket hand; Turns - NR: turns in the direction of the non-racket hand; au = arbitrary units; *significant difference between divisions 
Table 2 Differences in technical aspects of performance during sets of WT across different divisions. Values presented are means ( \pm SD)

\begin{tabular}{|c|c|c|c|c|c|c|c|}
\hline & \multirow{2}{*}{$\begin{array}{c}\text { Main effect } \\
\text { (division) }\end{array}$} & \multirow[t]{2}{*}{ Men's } & \multirow[t]{2}{*}{ Women's } & \multirow[t]{2}{*}{ Quads } & \multicolumn{3}{|c|}{ Effect sizes $( \pm 95 \% \mathrm{CI})$} \\
\hline & & & & & Men vs. Women & Men vs. Quad & Women vs. Quad \\
\hline Points per set (n) & 0.076 & $66(23)$ & $54(18)$ & $52(15)$ & $0.6(0.0,1.2)$ & $0.7(0.0,1.4)$ & $0.2(-0.5,0.8)$ \\
\hline $1^{\text {st }}$ serve $(\%)$ & 0.632 & $65.2(10.2)$ & $62.2(10.3)$ & $65.1(10.9)$ & $0.3(-0.3,0.9)$ & $0.0(-0.7,0.7)$ & $0.3(-0.4,0.9)$ \\
\hline Strokes per rally (n) & 0.005 & $3.2(0.5)$ & $3.1(0.8)$ & $2.5(0.5)$ & $0.2(-0.4,0.7)$ & $1.2(0.5,1.9)^{*}$ & $0.7(0.0,1.4)^{*}$ \\
\hline Shots off 1 bounce $(\%)$ & 0.138 & $85.7(6.8)$ & $82.1(7.6)$ & $81.5(6.2)$ & $0.5(-0.1,1.1)$ & $0.6(0.0,1.3)$ & $0.1(-0.6,0.8)$ \\
\hline Shots off 2 bounces $(\%)$ & 0.026 & $10.0(5.5)$ & $15.7(7.9)$ & $16.1(6.9)$ & $0.8(0.2,1.4)^{*}$ & $1.0(0.3,1.7)^{*}$ & $0.1(-0.6,0.7)$ \\
\hline Forehands $(\%)$ & 0.009 & $43.6(6.9)$ & $49.6(7.8)$ & $51.0(11.7)$ & $0.8(0.2,1.4)^{*}$ & $0.8(0.1,1.5)^{*}$ & $0.1(-0.5,0.8)$ \\
\hline Backhands (\%) & 0.040 & $51.8(7.7)$ & $48.0(7.6)$ & $45.0(8.9)$ & $0.5(-0.1,1.1)$ & $0.8(0.1,1.5)^{*}$ & $0.4(-0.3,1.0)$ \\
\hline Volleys (\%) & 0.237 & $4.6(3.8)$ & $2.4(1.9)$ & $3.6(3.5)$ & $0.7(0.1,1.3)$ & $0.3(-0.4,0.9)$ & $0.5(-0.2,1.1)$ \\
\hline Points won by server (\%) & 0.005 & $56.0(10.6)$ & $44.0(12.4)$ & $44.6(13.6)$ & $1.0(0.4,1.7)^{*}$ & $1.0(0.3,1.7)^{*}$ & $0.0(-0.7,0.8)$ \\
\hline Points won within 2 shots (\%) & 0.106 & $25.5(14.8)$ & $36.2(18.5)$ & $32.8(16.0)$ & $0.6(0.1,1.2)$ & $0.5(-0.2,1.2)$ & $0.2(-0.5,0.9)$ \\
\hline Winners & 0.100 & $0.29(0.09)$ & $0.33(0.12)$ & $0.26(0.10)$ & $0.4(-0.2,1.0)$ & $0.3(-0.3,1.0)$ & $0.6(-0.1,1.3)$ \\
\hline Errors & 0.196 & $0.21(0.08)$ & $0.19(0.04)$ & $0.22(0.05)$ & $0.3(-0.3,0.9)$ & $0.1(-0.5,0.8)$ & $0.7(0.0,1.4)$ \\
\hline Groundstroke winners & 0.085 & $0.20(0.06)$ & $0.23(0.09)$ & $0.18(0.07)$ & $0.4(-0.2,1.0)$ & $0.3(-0.3,1.0)$ & $0.6(-0.1,1.3)$ \\
\hline Return winners & 0.013 & $0.09(0.07)$ & $0.18(0.11)$ & $0.11(0.09)$ & $1.0(0.4,1.6)^{*}$ & $0.3(-0.4,0.9)$ & $0.7(0.0,1.4)$ \\
\hline Forehand winners $(\%)$ & 0.468 & $61.8(14.9)$ & $60.1(18.6)$ & $66.3(16.4)$ & $0.1(-0.5,0.7)$ & $0.3(-0.4,1.0)$ & $0.3(-0.3,1.0)$ \\
\hline Service winners & 0.143 & $0.03(0.03)$ & $0.01(0.02)$ & $0.05(0.07)$ & $0.8(0.2,1.4)$ & $0.4(-0.3,1.1)$ & $0.9(0.2,1.6)$ \\
\hline Volley winners & 0.003 & $0.04(0.03)$ & $0.01(0.02)$ & $0.01(0.01)$ & $1.2(0.5,1.8)^{*}$ & $1.2(0.5,1.9)^{*}$ & $0.0(-0.7,0.7)$ \\
\hline Winners off 1 bounce (\%) & 0.314 & $91.2(8.4)$ & $91.8(11.0)$ & $87.9(9.0)$ & $0.1(-0.5,0.6)$ & $0.4(-0.3,1.0)$ & $0.4(-0.3,1.1)$ \\
\hline Winners off 2 bounces ( $\%)$ & 0.049 & $4.9(7.0)$ & $7.6(10.3)$ & $12.2(9.0)$ & $0.3(-0.3,0.9)$ & $0.9(0.2,1.6)^{*}$ & $0.5(-0.2,1.1)$ \\
\hline Groundstroke errors & 0.561 & $0.27(0.09)$ & $0.24(0.06)$ & $0.25(0.08)$ & $0.4(-0.2,1.0)$ & $0.2(-0.4,0.9)$ & $0.1(-0.5,0.8)$ \\
\hline Return errors & 0.447 & $0.15(0.08)$ & $0.18(0.09)$ & $0.16(0.12)$ & $0.4(-0.2,0.9)$ & $0.1(-0.6,0.8)$ & $0.2(-0.5,0.9)$ \\
\hline Forehand errors $(\%)$ & 0.731 & $45.9(18.3)$ & $48.0(16.6)$ & $49.9(16.1)$ & $0.1(-0.5,0.7)$ & $0.2(-0.4,0.9)$ & $0.1(-0.6,0.8)$ \\
\hline Service errors & 0.062 & $0.06(0.06)$ & $0.07(0.05)$ & $0.10(0.06)$ & $0.2(-0.4,0.8)$ & $0.7(0,1.3)$ & $0.6(-0.1,1.2)$ \\
\hline Unforced errors $(\%)$ & 0.390 & $68.8(14.1)$ & $75.4(12.8)$ & $68.4(21.6)$ & $0.5(-0.1,1.1)$ & $0(-0.6,0.7)$ & $0.4(-0.3,1.1)$ \\
\hline
\end{tabular}

$\mathrm{Nb}$ - winners and errors are reported as a ratio to the number of points played; *significant difference between divisions 